\section{THE QUEST AND RECONSTRUCTION OF IDENTITY IN HARUKI MURAKAMI'S KAFKA ON THE SHORE ${ }^{1}$}

\section{Kanya Wattanagun ${ }^{2}$ Suradech Chotiudompant ${ }^{3}$}

\begin{abstract}
This essay aims to explore the issue of identity quest of various characters in Haruki Murakami's "Kafka on the Shore." While Hoshino is portrayed as an alienated citydweller, whose identity formation depends on superficial signs produced in consumer society, Satoru Nakata's identity is noted for its marginalized position as he is unable to make sense of capitalist logic. His viewpoint reveals a hidden side of capitalist society that glorifies such superficial consumption of empty signs in the process of identity construction. In contrast to Hoshino and Nakata, Murakami's portrayal of Kafka Tamura suggests a solution to identity quest when Kafka is able to stabilize his shattered identity through redefinition of memories and reflections.
\end{abstract}

\footnotetext{
${ }^{1}$ This essay was developed from the MA thesis titled "Magical Realism and Intertextuality in Haruki Murakami's Kafka on the Shore" under the sponsorship of the Ninetieth Anniversary of Chulalongkorn University Scholarship of the Ratchadapiseksompot Fund.

${ }^{2}$ Lecturer, Department of Western Languages and Literature, Ubon Ratchathani University, Ubon Ratchathani, Thailand

${ }^{3}$ Lecturer, Department of Comparative Literature, Chulalongkorn University, Bangkok, Thailand
}

\section{Introduction}

Identity seems to be one among various issues tackled in Haruki Murakami's works. In his novel Kafka on the Shore, Murakami points out how individual identity is constructed through the domain of signs. These signs are not merely limited to such simple products as a baseball cap or an aloha shirt, but also include narrative and memory. Through them, a sense of coherence is bestowed on an individual's existence. In addition to the reliance upon such aspects, identity construction also takes place in the inner world, another dimension that is more personal in the borderline between the psychological and the social. Through the portrayal of the protagonist's identity construction initiating in his inner realm, Murakami suggests the ways in which one can negotiate with the regime of signs, redefining them and thereby weaving meaningful stories which would become the solid ground for his precarious identity.

\section{Identity quest in capitalist society}

Kafka on the Shore relates the story of a fifteen-year-old boy who names himself after Franz Kafka. The Oedipal relationship between him and his father resolves into mutual hatred and drives the boy away from home. His journey could be regarded as an allegory of empty self in search of stable identity. Encountering many bizarre incidents as well as experiencing emotional attachment, Kafka gradually develops a whole, stable identity. Hoshino and Nakata play supporting roles that significantly reveal how individual identity is constructed via symbolic consumption, and how it can lead to alienation. While Hoshino represents a person residing within capitalist society, leading his life conforming to its ideology, Nakata personifies a marginal viewpoint, 
the subversive quality of which exposes us to the hidden 'unreal' side of capitalism.

Nakata is a dumb old man who can neither read nor write. After stabbing Kafka's father to death, Nakata leaves Tokyo and runs into Hoshino, a truck driver who agrees to give the old man a lift. The novel relates Hoshino's obsession with aloha shirts:

He decided it was about time for a new aloha shirt and scoured a few shops looking for one. ... Summer or winter alike he always wore aloha shirts, but that didn't mean any aloha shirt would do ...

(Murakami 2005: 337).

In addition to the shirts, a Chunichi Dragons baseball team cap and comics also function as signs giving a sense of coherence to his identity. This argument is sustained by Hoshino's confusion while pondering his identity. Such an empty man he is that Hoshino clings to these inanimate objects:

Sunk back in his soft chair, ... a number of thoughts crossed his mind-mostly having to do with himself. But the more he thought about himself, the less reality his existence seemed to have. $\mathrm{He}$ began to feel like some meaningless appendages sitting there. I've always been a great fan of the Chunichi Dragons ... but what are the Dragons to me, anyway? ... So why the heck have I spent all this time getting worked up like the team was some extension of myself? Mr. Nakata said he's empty. Maybe he is, for all I know. But what does that make me? He said an accident when he was little made him that way-empty. But I never had an accident. If Mr. Nakata's empty, that makes me worse than empty!

(Murakami 2005: 338)

In this case, what Hoshino consumes to construct his identity is his allegiance to the Chunichi Dragons baseball team. Declaring himself to be a fan of the team and indulging in it as if 'the team was some extension' of himself, it becomes a concrete sphere to which Hoshino feels attached, implanting in his mind an awareness that he is a member of a group which has its own goal and mission. For Hoshino, the Chunichi Dragons baseball team cap functions as a signifier that helps with his identity formation. In capitalist society where it is difficult to find the essence of one's existence, undermined as it was by the consumption of empty signs and the ceaselessly provoked desire to consume, a person needs to construct and reiterate his identity through the signs he selects. Nevertheless, what is acquired from these signs are mere images, turning identity into an unstable body. In this light, objects actively mediate in the process of identity construction as they project various images onto a rather passive body.

This may be the reason why Hoshino still feels empty even though he is equipped with many objects which, brought together, become a unique combination distinguishing him from others. Hoshino's feeble identity can perhaps be regarded as one of the main conditions to which people are subject when they are so accustomed to consuming empty signs. Japanese scholar Otsuka Eiji describes this condition as follows:

The Japanese are no longer the producers. Our existence consists solely of the distribution and 
consumption of "things" brought us from elsewhere, "things" with which we play. Nor are these "things" actually tangible, but are instead only sign without any direct utility in life. None of what we typically purchase would, were we deprived of it, be a matter of life or death. These "things" are continually converted into signs without substance, signs such as information, stocks, or land. What name are we to give this life of ours today?

(Otsuka cited in Treat 1993: 353)

Within the regime of empty signs, alienation originates from the contradiction between ideology and the real condition in which one lives. To be more precise, capitalist ideology implants on people's mind that the possession of materialssuch as a big house or a car of the latest model-indicates a 'good' life. However, after pursuing this normative quest for material wealth, some people might discover that it leads to nothing except a hoarding of material signs that signify achievement. They may then recognize that what capitalist ideology promises to offer to those subjected to its norms are not as ideal as they are supposed to be. Hoshino's case is a good example of how a person is disillusioned and begins to realize the full picture of capitalist ideology.

Alienation conjured up by capitalism is not the sole reason for Hoshino's empty self. His detachment from both individual and collective memories is another prominent factor restraining his development of solid identity. Without stories or memories which he can use to describe who he is or where he comes from, there is no stable ground for Hoshino's identity to be shaped. His lack of collective memory is apparent when he says to Nakata that Japan has never been occupied by America:

"Japan was occupied by the Americans back then. The seashore at Enoshima was filled with American soldiers."

"You gotta be kidding." "No, I'm not kidding."

"Come on," Hoshino said "Japan was never occupied by America." (Murakami 2005: 227)

Hoshino's ignorance of such a crucial incident in Japanese history emphasizes his distance from collective memory. His lack of this historical knowledge may be construed as a sense of non-belonging: that he is not related to, or is not a part of his community. Such rootlessness contributes to Hoshino's empty identity, as he does not possess stories from the past, in this case those that have something to do with his own country.

Hoshino's self is remedied after his persistent encounters with magical incidents. In this respect, magic functions as a rupture hidden beneath capitalist norms. While life in capitalist society which is supposed to be something 'real' paradoxically contributes to alienation, life amidst bizarre incidents turns to be something meaningful, motivating a person to reflect on his existence. The first quote displays how Hoshino contemplates his life before meeting Nakata and the second depicts his transformed viewpoint after experiencing magical phenomena:

I.

Hoshino was drawn back to his childhood. He used to go to the river every day to catch fish. Nothing to worry about back then, he reminisced. ... As long as I was 
alive, I was something. That was just how it was. But somewhere along the line it all changed. Living turned me into nothing. Weird.... People are born in order to live, right? But the longer I've lived, the more I've lost what's inside me-and ended up empty. And I bet the longer I live, the emptier, the more worthless, I'll become. (Murakami 2005: 341)

II.

"These past ten days there's been a lot of bizarre stuff going on. Leeches falling from the sky, Colonel Sanders popping up out of thin air, hot sex with this dropdead-gorgeous philosophy major, swiping the entrance stone from that shrine ... A lifetime of weird stuff packed into ten days. ... The most amazing thing of all has been you, Mr. Nakata. You changed my life. These past ten days, I don't know-things look different to me now. Stuff I never would've given a second glance before seems different. ... It's been one of the most meaningful times I've ever had in my life. (Murakami 2005: 426)

Magical occurrences highlight another side of reality hidden by capitalist ideology. Magic in Kafka on the Shore thus conveys a hopeful message. Apart from reminding readers of the oppressive aspects of reality created by capitalism, the emergence of such occurrences implies that though we cannot totally turn our backs from this reality in which we live, we can at least gain an awareness of how oppressive it can be and how another dimension of such a reality can be foundan alternative view that can be both refreshing and rejuvenating. In this light, what heals Hoshino's alienated self is actually his transformed viewpoint triggered by his friendship with Nakata and 'a lot of bizarre stuff' he has encountered. Murakami possibly suggests that, in face of such a capitalist reality, what we need is a critical perspective that enables us to view this reality differently and more profoundly.

By contrast, Satoru Nakata is explicitly marginalized due to his inability to make sense of capitalist logic. Whereas Hoshino's emptiness is conjured up by his constant consumption of empty signs, Nakata's alienated self is generated from his incapacity to understand language and familiar concepts generally accepted as unalterable facts. The difference in the nature of their alienation means that their subversive roles function differently. While Hoshino's case draws the reader's attention to the negative side of capitalism, of how those living under its norms develop fragmented identity and feel empty inside, Nakata's case reveals the unreal aspect of this establishment which becomes prominent through his marginal but acute viewpoint.

Nakata is an old man labeled as a 'dumb' due to his illiteracy. Despite his deficiency in language, he is equipped with magical powers. His mindset is influenced by a logical system that differs from that of capitalism. Nakata can see through familiar images people generally think of capitalism and regard them in a different light. Nevertheless, his inability to comprehend language hints that he never perceives himself as an individual with a unique identity. This assumption is supported by the fact that while conversing with others, Nakata initially addresses himself by the name 'Nakata' instead of using ' $I$ ': 
"Nakata's quite hungry"

(Murakami 2005: 315).

"Nakata has a favor to ask you, Mr. Hoshino."

(Murakami 2005: 322)

His inability to capture the meaning of ' $\mathrm{I}$ ' is not only related to his illiteracy, but can also be considered in light of the (post-) structuralist theory that language is the primary source through which a person becomes familiar with the concept of differentiation. According to Jacques Lacan (1981), an infant initially perceives itself as a partial organism unified with its mother. This consciousness is altered in the mirror stage when the infant sees its reflection in the mother's eyes and recognizes itself as a whole being separated from her. Then during the symbolic stage, this realization is reinforced when the infant learns language through which it becomes acquainted with the concept of differentiation and begins to distinguish itself from others. In this paradigm, Nakata's incapacity to make sense of the linguistic sign of 'I' can be related to his inability to differentiate between himself and others.

Because of a magical event that happened to him when he was young, Nakata's memory has been entirely erased, diminishing his ability to consider general matters based on capitalist logic. He has no conceptual framework that enables him to divide the 'poor' from the 'rich'. He cannot figure out how a great amount of money in his bank account can be more important than a few coins in his pocket. Nakata's confusion is clearly depicted in the text:

Nakata had no idea what a resort condo was, or what 'investing' meant, nor did he understand what taking out a 'loan' involved. He lived in a world circumscribed by a very limited vocabulary.

Only amounts up to fifty dollars also had any meaning to him. Anything above that-a thousand dollars, ten thousand-was all the same to him. A lot of money, that's all it meant. He might have savings, but he'd never seen it. They just told him 'this is how much you have in your account' and told him an amount, which to him was an abstract concept. So when it all vanished he never had the sense that he'd actually lost something real. (Murakami 2005: 225)

Through Nakata's incompetence to capture the value of familiar artifacts such as money and bank accounts, Murakami indicates that these items sought after by people in the capitalist world are actually simulacra which are nothing more than empty signifiers. In this light, money is simply an imaginary item, whose value is derived from the arbitrary presumption of a group of people. It is not surprising then that Nakata can only comprehend the value of a small sum of money that he can really exchange for something he needs, but cannot imagine the meaning of those figures printed in his account book. This is not because of his 'dumbness' which prevents him from accessing their meaning given in the capitalist world, but because these items never possess any 'real' meaning for him from the start.

Despite their differences, Nakata's and Hoshino's roles share a common feature: they both function as a rupture within consensus reality. In addition, Nakata and Hoshino represent two different types of 
alienated identity in face of capitalism. The first one, demonstrated through Hoshino's role, is the feeble identity derived from the consumption of empty signs. Alienation therefore emerges from an awareness that one does not fit in with the norms to which the majority of people conform. The second one, represented by Nakata's role, is the alienation forced upon a person by others due to his different outlook or practice. In sum, both Nakata and Hoshino symbolize identities which are oppressed under the totalitarian system of capitalism.

\section{A journey back to the inner world: the reconstruction of shattered identity}

Kafka Tamura's problematic identity is manifest from the very first chapter. In the scene where he converses with his alienated self, sometimes appearing in the form of another teenage boy and at other times a black crow, it becomes apparent that Kafka possesses a split identity. However, his alienated side -'the boy named Crow'-does not seem to harm him. On the contrary, it functions as his conscience when the protagonist is overcome by dark wild passion. However, Kafka's shattered self is not as much the result of capitalism as in the cases of Hoshino and Nakata. Instead, it develops from the perverted relationship between him, his father and a woman who is supposed to be his mother. Abandoned by mother and psychologically abused by father, his identity takes its form among various antagonistic currents. Torn between the hatred for his father and the unfulfilled yearning for his mother, Kafka develops self-hatred which is the basis of his identity formation. In this light, his departure from home can be considered a symbolic portrayal of the identity quest. Bizarre incidents Kafka encounters during his journey gradually lead him back to the core of his shattered self.

One of the main factors indispensable for the remedy of Kafka's identity is magic, as it motivates the boy to attach himself emotionally with certain places, memories, stories, and people. Magical events happening to Kafka are comparatively different from those Hoshino encounters. In Hoshino's case, magic inspires him to employ a different perspective that enables him to reconsider his life and position in capitalist society. However, the magic that Kafka confronts plays a part by evoking his suppressed emotions. Provided that individual identity partially develops from a tendency to relate one's self to the group, Kafka, who deliberately secludes himself from society, therefore has no object with which to identify himself. Magic, which enables him to have emotional investment, links him back to the outside world, thus beginning the process of identity formation.

In the scene where Kafka confronts a 'living spirit', ${ }^{4}$ the reader may sense the nostalgic, sad feeling overwhelming the protagonist. The atmosphere created by

\footnotetext{
${ }^{4}$ According to the belief during the Heian period (794-1185 A.D.), a person overwhelmed by negative emotions would become a living spirit at night in order to fulfill the deed he could not openly commit during the daytime due to guilt and shame. This supernatural phenomenon is mentioned in The Tale of Genji, an ancient Japanese literary work written by Murasaki Shikibu. In the episode named 'Aoi', the living spirit of Lady Rokujo-one of Prince Genji's lovers-takes possession of Lady Aoi, who is Genji's consort pregnant with his child. Overcome by jealousy, Rokujo's spirit departs from her body and tortures Aoi to death.
} 
this incident is considerably different from the scene of Hoshino's encounter with Colonel Sanders (Murakami 2005: 296), in which the narrator relates the character's reaction to magical incidents in a humorous way.

She's sitting at the desk, chin resting in her hands, staring at the wall and thinking about something. Nothing too complex, I'd say. It looks more like she's lost in some pleasant, warm memory of not so long ago. Every once in a while a hint of a smile gathers at the corners of her mouth. ...

She's got to be a ghost. First of all she's just too beautiful. Her features are gorgeous, but it's not only that. She's so perfect I know she can't be real. She's like a person who stepped right out of a dream. The purity of her beauty gives me a feeling close to sadness -a very natural feeling, though one that only something extraordinary could produce. (Murakami 2005: 228)

Having neither beautiful memories to nurture, nor intimate relationships to maintain, nor emotional attachment with certain objects to which to bind himself, Kafka is psychologically shut out from potential channels that would have enabled him to restore his shattered identity. The emergence of living spirit, stirring the sad, nostalgic feeling within him, links the boy to one of these channels. The powerful feeling will stimulate Kafka to view his life and the outside world from different eyes. In this light, bizarre incidents occurring in his life then play the role of tragedy with their cathartic ability to trigger powerful sensations and thereby bring about the dramatic transformation within the protagonist's inner world. Through Kafka, Murakami suggests another way of identity construction, the one that is different from what Hoshino employs. Instead of consuming empty signs to absorb their images and defining them as one's identity, Kafka uses his feelings as a vehicle to form a different perspective and redefine things around him, including the essence of his existence. During the era when individual perception is controlled by many devices in various manners, the emotional domain may be a site where he can to some extent maintain his agency. These feelings, which instinctively and naturally well up unrestrained by reason or other influential factors, inspire Kafka to redefine what has already been designated by society, especially his existence.

Kafka's transformed internal world is only the first step to identity construction. What is derived from this initial progress is the concern on Kafka's part to see things around him differently, replacing the numb feeling arising from an empty life he has lived. Another device subsequently in use is the memory from which the protagonist fabricates his story. Despite his lack of 'good old days' to be converted into the positive 'site of memory', ${ }^{5}$ he is still able to form a new identity again in

\footnotetext{
${ }^{5}$ According to Gaston Bachelard (cited in Wilson 1995: 216), memory connects to space as it is usually conjured up by the presence of a specific place related to the event or experience a person memorizes. Saeki's living spirit repeatedly occurring in the same place at the same time may exemplify this notion. In this light, Kafka's bedroom in Komura Monumental Library, where Saeki and her lover once spent their time together, is 'the site of memory' where what happened in the past repeats itself.
} 
the end of the story. Kafka adopts two objects of desire to substitute what he lacks in reality. Miss Saeki and Komura Monumental Library are what Kafka uses to satisfy his unfulfilled desire: the former for the absent mother and the latter for the site of memory.

Miss Saeki is the manager of Komura Monumental Library, where Kafka stays during his departure from home. Her memory is frozen in a specific time when Saeki and her lover were bound tightly together. However, this complete union was abruptly shattered when her boyfriend moved to Tokyo and was murdered there. Unable to overcome this loss, Saeki rejects the present time she deems inauthentic and nurtures her existence by the memory of the time she once shared with her lover. The text represents Saeki's nostalgia through the magical mode. Her living spirit departs from her body every night in order to return to the room once owned by her lover and gaze at his portrait on the wall. The emergence of Saeki's living spirit is seen by Kafka. When he beholds Saeki's living spirit, feeling that "[i]t looks more like she's lost in some pleasant, warm memory of not so long ago", this hints at a sense of nostalgia stirred up within Kafka. However, this does not stem from the occurrence he perceives, but rather from the manner Kafka interprets this situation. Briefly, Kafka is preoccupied by the desire to immerse himself in a certain time, a memory he can return to and have his alienated self healed. The living spirit is the object on which Kafka projects his unfulfilled desire as well as the medium launching Kafka into Saeki's past which is subsequently appropriated as his own. A conversation between Kafka and Saeki reveals that he 'borrows' her memory to satisfy his desire:
"I think you're trying to make up

for lost time."

... "You may be right,"

... But how do you know

that?"

"Because I'm doing the same

thing."

"Making up for lost time?"

"Yes," ... "A lot of things were stolen from my childhood. Lots of important things. And now I have to get them back." "In order to keep on living."

..."I have to. People need a place they can go back to. There's still time to make it, I think. For me and for you."

... "Who are you?" ... "And why do you know so much about everything?"

You tell her she must know who you are. I'm Kafka on the Shore, you say. Your lover-and your son. The boy named Crow. And the two of us can't be free. (Murakami 2005: 332)

Kafka's effort to 'make up for lost time' is achieved through the narrative he fabricates in order to bind himself with Saeki. Collecting some information of Saeki's past beforehand, Kafka fills the mysterious space in her story with his presence. The duration between Saeki's disappearance after her lover has passed away and her resettlement in Takamatsu is an ambiguous period of time open for various interpretations. For Kafka, he selects to decipher this mystery in the way that suits his desire for the absent mother, as he clings to the conjecture that Saeki is the mother who left him. Named by Kafka as his mother, Saeki immediately becomes the object of desire substituting the boy's real mother. Through this substitution, which in this case is achieved via sexual 
intercourse, ${ }^{6}$ Kafka is able to form a new identity freed from the haunted past.

\footnotetext{
${ }^{6}$ Sexual intercourse in this case denotes a sacred act mother and son perform together in order to have their inner worlds linked and thereby 'achieve' what they need from each other's presence. In this remarkable scene, sexual intercourse may symbolize the protagonist's return into his mother's womb to the original state when an infant perceives itself as an organism united with the mother and impenetrable by the symbolic rule or the rule of Father.
}

And you're sucked into the time warp. Before you know it, her dream has wrapped itself around your mind. Gently, warmly, like amniotic fluid ... you're trying to find the direction of the flow, struggling to hold on to the axis of time. But you can't locate the borderline separating dream and reality. Or even the boundary between what's real and what's possible. ... Little by little you're sucked down into the warm mud. The whole world turns warm, wet, indistinct, and all that exists is your rigid, glistening cock. You close your eyes and your own dream begins. It's hard to tell how much time is passing. The tide comes in, the moon rises. And soon you come. (Murakami 2005: 293)

In this narrative there are many signs symbolizing the condition in the womb. Amniotic fluid, the tide and the moon are all symbols related to femininity. Kafka's helplessness as symbolized by his inability to draw the distinct line between dream and reality hints that the boy is regressing to the presymbolic stage when the infant has no concept of differentiation. Additionally, while having sexual intercourse both Saeki and Kafka do not utter a word, this feature implies that they are back to the realm where both the symbols and the symbolic rule are not present. Kafka's awareness of the self is totally erased
The acquirement of the object of desire is not the only medium through which Kafka fulfills his desire. Similar to the manner Kafka craves for mother, he demands mother to long for him in return. In other words, what he requires is not merely the reunion with mother but his wish to be her object of desire. These ambivalent roles are accomplished through another liaison Kafka has with Saeki's story. In addition to the make-believe claim that she is his mother, Kafka identifies himself as Saeki's lover, who returns to her to 'make up for the lost time'. Through this new role, Kafka marks his position within Saeki's story and begins to reshape his self-awareness in a new light. The fabricated narrative of selfhood links the protagonist with the 'feign' memory functioning as the substitute for the real, meaningful story Kafka lacks.

With the memory as the basis of identity formation, the final step Kafka takes in order to fulfill the whole procedure is the return to the core of his being, signified by his journey to the magical village in the midst of a dense forest. In most of Murakami's works, the protagonist's

and substituted by the identification with a certain organ-in this case, his 'rigid, glistening cock'. According to Lacan, the phallus is an identification object with which a male infant identifies itself during the onset of identity construction. This feature is different from that of a female infant whose genital 'furnishes only an absence' (Lacan 1981: 198-199) and therefore develops the penis envy not because of its subjection to phallocentricity but of its longing for an identification object. Kafka's recognition of his existence via his erected phallus implies that he is regressing to the presymbolic stage when he and mother are one. In sum, sexual intercourse brings the protagonist back to the desirable stage unable to be retrieved in reality and thereby appeases his yearning for the absent mother. 
crossing beyond the boundaries into a mysterious world stands for the return to the core of one's self in order to meet 'the internal Other' residing in one's own unconscious. ${ }^{7}$ For Kafka, this journey is indispensable for the formation of a new identity because the main impetus of the boy's shattered self is his love-hate relationship with the absent mother. On one hand, the moment the mother turns away and leaves the boy alone becomes the trauma chiselled in Kafka's memory, alienating the boy's self. ${ }^{8}$ On the other

\footnotetext{
${ }^{7}$ According to Matthew C. Strecher, the grotesque realms protagonists are magically lured into signify the journey back to the unconscious world or 'the core of identity'. Strecher cites as examples the protagonists in Murakami's two novels Dance Dance Dance and The Wind-up Bird Chronicle. He presents the argument as follows:
}

\section{The protagonist of Dansu dansu dansu discovers a musty, dust-filled room in a deep corner of his mind, again, dark, gloomy, and filled with dust-covered memories that he cannot make sense of. Another room is filled with dusty skeletons, literally the skeletons of his past. And in Nejimakidori kuronikuru, his unconscious is presented as an enormous, maze-like hotel, in which "Room 208" is the core, the centre of his whole being. It is this centre, the location of the core identity, that concerns us here. (Strecher 1999: 270)}

${ }^{8}$ In this scene, when the mother turns her face away from four-year-old Kafka, who is sitting on the porch, the boy narrates how a part of him slips away and transforms into a black crow. The crow flies to a tree from where it stares down to the boy, unaffected by the emotional crisis the boy is confronting. This incident is related as follows:
My mind wanders back to my house on the day my mother left, taking my sister with her. I'm sitting alone on the porch, staring out at the garden. ... I'm alone in the house. I don't know why. But I already knew I was abandoned. I understood even then how this would change my world forever. Nobody told me this-I just knew it. The house is empty, deserted and abandoned lookout post on some far-off frontier. I'm watching the sun setting in the west, shadow stealing over the world. In a world of time, nothing can go back to the way it was. The shadows' feelers steadily advance, eroding away one point after another along the ground, until my mother's face, there until a moment ago, is swallowed up in this dark cold realm. That hardened face, turned away from me, is automatically snatched away, deleted from my memory....
I try to feel what she felt then and get closer to her viewpoint. It isn't easy. I' $m$ the one who was abandoned, after all, she was the one who did the abandoning. But after a while I take leave to myself. My soul sloughs off the stiff clothes of the self and turns into a black crow that sits there on a branch high up in a pine tree in the garden, gazing down at the four-year- old boy on the porch. I turn into a theorizing black crow. (Murakami 2005: 417-418)

This incident has profoundly traumatized Kafka. Kafka's psychological domain conducts a self-defense mechanism in the form of an alter ego who is free from emotional burden. This implies that the pain from being abandoned is too intense for a young boy to endure. Therefore, he has to imagine himself as a black crow devoid of human emotion. Besides, the manner Kafka's consciousness deletes the image of mother's face from his memory is similar to the psychological 
hand, Kafka's unfulfilled desire for the absent mother jeopardizes his inner world preventing him from developing the solid ground for identity construction. Even though this desire is to some extent satisfied through his reimagining of Saeki, considered as the mother figure, the fulfillment is only temporary since desire is appeased through a substitute which cannot completely capture the entire extent of what it represents. Therefore, rather than immersing in Saeki's presence and his relationship with her which can only satisfy the superficial layer of desire, Kafka needs to overcome his lack and learn to live with absence.

Kafka's liberation from trauma and unfulfilled desire is manifest when the boy ventures into the dense forest and later discovers a village in the midst of it. The impact of the surroundings on his psychology hints that Kafka is losing himself in the labyrinth of his unconscious affected by trauma and negative memories. Kafka's venture through the dense forest may then symbolize his penetration into and reformation of his inner self. The circumstance surrounding Kafka symbolically represents his state of mind haunted by traumatic memory.

Occasionally there's some weird sound. A thud like something hitting the ground, a creak like floorboards groaning under weight,

reaction against traumatic experience. Because of its negative impact on an individual's mentality, traumatic experience is immediately deleted and this obliteration leaves the vacant space within the memory. Via this vacant space, trauma repeats itself and comes back to haunt its victim. In Kafka's case, the obscure image of his mother's face seems to remind him of her existence as well as repetitiously launches him to the past behind its obscurity. and others I can't describe. I have no idea what these mean, since there's no knowing what they are. Sometimes they sound far away, sometimes right near by-the sense of distance expanding and contracting. Bird wings echo above me, sounding louder, more exaggerated, than they should. Every time I hear this I stop and listen intently, holding my breath, waiting for something to happen. Nothing does, and I walk on. ... Still, as I walk along I get the feeling something, somewhere, is watching me, listening to me, holding its breath, blending into the background, watching my every move. Somewhere far off, something's listening to all the sounds I make, trying to guess where I'm headed and why. I try not to think about it. The more you think about illusions, the more they will swell up and take on form. And no longer be an illusion. (Murakami 2005: 400-401)

It seems there is an unidentified creature following Kafka. However, we cannot specifically indicate whether it really exists. Kafka senses some sounds and gazes but he is unable to figure out where they come from. This ambiguous state is relevant to the nature of trauma, as it is a negative experience deleted from memory, pushed to the state of absence unreachable by the conscious. However, its impact is too intense to be entirely erased so it comes back to haunt a person through the vacant space within his memory. In other words, the presence of trauma is emphasized via the absent memory reminding that there once happened a traumatic incident but it negatively affects one's psyche so profoundly that the 
conscious rejects to remember. In Kafka's case, his psychological realm materializes the nature of his trauma in the form of uncanny sound and haunting feeling of being gazed at. Besides, Kafka's inability to put his nervousness into words, addressing this disturbing state by the unspecified third pronoun, manifests the nature of trauma which recurs in the form of fragmented experience beyond the conscious realm. One of the steps Kafka has to take in reconstructing his identity is to confront and revise this haunting experience.

This redefinition occurs when Kafka reaches a village located in the midst of the forest where he meets Saeki and her alter ego. Both she and her double represent two forms of desire dwelling in Kafka's unconscious. The fifty-year-old Saeki is considered the mother figure that enacts the emotional abuse Kafka's absent mother forced on her son. This role Saeki performs is different from that of her alter ego. The fifteen-year-old Saeki Kafka meets as a living spirit is the object of desire with which Kafka attaches himself and through which he inserts his presence into Saeki's past. Precisely, the young Saeki is the liaison connecting Kafka with the old Saeki. However, the fulfillment conducted via the substitute cannot get to the real essence of it; this is similar to how a sign cannot completely capture the essence of what it signifies. On the other hand, the more one tries to make the substitution with an attempt to subdue his desire through the substitute, the farther one is swept away from the real extent of his desire and thus has to repeatedly consume the substitute. Hence, the boy's contact with Saeki temporarily fulfills his desire and simultaneously adds another distorted layer to its essence. Struggling in this vicious circle, Kafka is in the grip of desire and therefore unable to form a new identity. In order to break away from this circle, Kafka needs to learn to negotiate with unfulfilled desire. His acceptance of this is demonstrated by his return to the real world without Saeki.

In the scene where Kafka meets Saeki in the village, Saeki's thoughts and reflections free the boy from painful memory caused by his experience of being abandoned. Her narrative and Kafka's reaction are illustrated as follows:

"A long time ago I abandoned someone I shouldn't have. ... Someone I loved more than anything else. I was afraid someday I'd lose this person. So I had to let go myself. If he was going to be stolen from me, or I was going to lose him by accident, I decided it was better to discard him myself. ... It was someone I should never have abandoned."

"You were discarded by the one person who never should have done that" ... "Kafka-do you forgive me?"

... "Miss Saeki, if I really do have the right to, then yes-I do forgive you," I tell her.

Mother, you say. I forgive you. And with those words, audibly, the frozen part of your heart crumbles. (Murakami 2005: 462)

The real nature of the relationship between Kafka and Saeki still maintains its ambiguity to the end. Even in this event, the text does not explicitly point out whether they are real mother and son. This ambiguity corresponds with the function Saeki's narrative fulfills; that is to say, 
Kafka uses Saeki's utterance as the explanation to justify his mother's departure. In other words, through Saeki's reflection, the protagonist approaches traumatic experience from his mother's standpoint and thereby has it revised in a more positive light.

With the trauma redefined, the successful formation of Kafka's new identity is hinted at by his decision to return to society. His separation from Saeki implies the departure from the chain of substitution and Kafka's self-adjustment. Kafka's new identity is assured in the final scene when the boy catches an express train back to Tokyo and then falls asleep. Crow's words addressed to Kafka suggest that, after the long quest, the protagonist succeeds in having his identity reconstructed.

"You'd better get some sleep," ... "when you wake up, you'll be part of a brand new world."

You finally fall asleep. And when you wake up, it's true.

You are a part of a brand-new world. (Murakami 2005: 462)

The complete process of identity formation is assured in this final scene. In Kafka's case, forming new identity is a personal task fulfilled through the reworking over traumatic memories and reintegration into society.

\section{Conclusion: individual identity amidst social transformation}

Via the three characters in Kafka on the Shore, Murakami depicts his outlook concerning individual identity in various ways. Hoshino's case is the portrayal of problematic identity originating from the constant consumption of empty signs. Amidst capitalist society where an attempt to signify one's identity involves the association with an object or an image, Hoshino immerses himself in this chain of signification and becomes alienated.

Nakata's identity manifests another critical implication. Nakata's 'empty' self defined by capitalist ideology questions the norms established by this system. Through the role Nakata performs, Murakami raises an acute question: is the old man labeled as dumb and empty due to his real physical limitations or due to social discrimination? Nakata's empty self functions as an apparatus Murakami employs to reveal oppressive capitalist norms.

In Kafka on the Shore, readers might recognize the portrayal of reciprocal relationship between individual and society. On the surface, we might see how Nakata's and Hoshino's identities are determined in a social framework. Whereas the former is defined as a person without identity owing to his practical and ideological departure from capitalist norms, the latter fabricates his identity from images offered to him via consumable products. However, this portrayal alters when the identities of the characters are analyzed. Nakata's and Hoshino's 'problematic' identities as depicted in the text reflects Murakami's outlook toward 'problematic' reality he recognizes in his society. The inflation of mere signs without meanings, people's indulgence in consumerism and capitalism, and the alienation experienced by those who in one way or another turn against established norms, are its negative sides. Without Hoshino's inexplicable unease or Nakata's emptiness, the rupture hidden beneath what seems to be a homogenous society might not become apparent. 
Amidst consumerist society where one's identity is signified through consumable artifacts, a way to escape from this chain of signification and to develop a more solid identity is self-exploration occurring when a person ventures into his inner world and from there approaches the external world in a different manner. This seems to be the solution Murakami proposes through the development of Kafka, who delves deep down into his inner realm and has his identity reconstructed through the appropriation and redefinition of others' stories and memories.

\section{References}

Lacan, Jacques. 1981. Le Séminaire de Jacques Lacan. In Les Psychoses, edited by Jacques-Alain Miller, vol 3: 198-99. Paris.

Murakami, Haruki. 2005. Kafka on the Shore. New York: Vintage International.

Strecher, Matthew C. 1999. Magical Realism and the Search for Identity in the Fiction of Murakami Haruki. Journal of Japanese Studies 25.2: 263-298.

Treat, John Whitter. 1993. Yoshimoto Banana Writes Home: 'Shojo' Culture and Nostalgic Subject. Journal of Japanese Studies 19.2: 353-387.

Wilson, Rawdon. 1995 The Metamorphoses of Fictional Space: Magical Realism. In Magical Realism: Theory, History, Community. edited by Lois Parkinson Zamora and Wendy B. Faris, pp. 209-233. Durham and London: Duke University Press. 